\title{
CARACTERÍSTICAS VEGETATIVAS E SEUS EFEITOS SOBRE A PRODUÇÃO DE BANANEIRA EM TRÊS CICLOS ${ }^{1}$
}

\author{
LAURO SARAIVA LESSA ${ }^{2}$, TADÁRIO KAMEL DE OLIVEIRA², EDSON PERITO AMORIM ${ }^{3}$, \\ GISELLE MARIANO LESSA DE ASSIS², SEBASTIÃO DE OLIVEIRA E SILVA ${ }^{3}$
}

RESUMO - A produtividade em bananeira é um caráter complexo que resulta da associação de diferentes fatores, influenciados pelo ambiente. Este trabalho teve por objetivo estudar os efeitos diretos e indiretos de características vegetativas sobre a produção de bananeira em três ciclos. O trabalho foi conduzido no campo experimental da Embrapa Acre, em Rio Branco, Acre, entre os anos de 2003 e 2006. Foram avaliados 13 genótipos de bananeira (Preciosa, Japira, Pacovan-Ken, Pacovan, BRS Platina, Prata-Anã, ST12-31, Nanicão, Grande Naine, Calipso, Ambrosia, Bucaneiro e FHIA-02), no espaçamento de $3 \mathrm{~m}$ x 2 m, no esquema de blocos ao acaso, com cinco repetições. Determinaram-se a altura de plantas, diâmetro do pseudocaule, número de folhas na floração e na colheita, peso do cacho e número de pencas no cacho. Realizou-se a análise de variância para cada ciclo e estimaram-se os coeficientes de correlação fenotípicos e os coeficientes de trilha. Adotou-se como variável básica o peso do cacho, e as demais, como variáveis explicativas. O estudo dos efeitos diretos e indiretos evidenciou que o caráter produção é bastante influenciado pelo ambiente no primeiro ciclo, e, nos ciclos seguintes, a produção é muito influenciada pelas características vegetativas, principalmente número de folhas na colheita.

Termos para indexação: Musa spp., melhoramento genético, análise de trilha.

\section{VEGETATIVE TRAITS AND YOUR EFFECTS ON PRODUCTION OF BANANA EVALUATED IN THREE CYCLES}

Abstract - The productivity in banana is a complex character that results from the combination of different factors, influenced by environment. This work aimed to study the direct and indirect effects of vegetative traits on production in three cycles in banana. The work was conducted in the Experimental Field of Embrapa Acre in Rio Branco, Acre, among years 2003 and 2006. Thirteen genotypes of banana (Preciosa, Japira, Pacovan Ken, Pacovan, BRS Platina, Prata Anã, ST12-31, Nanicão, Grande Naine, Calypso, Ambrosia, Bucaneiro and FHIA 02) were evaluated, spaced $3 \mathrm{~m} \times 2 \mathrm{~m}$, in the randomized blocks with five replicates. The evaluated traits were: plant height, diameter of pseudostem, number of leaves at flowering and harvest, weight of bunch and number of hands in the bunch. Analysis of variance and path analysis were carried out for each cycle and phenotypic correlation coefficients were estimated. The trait weight of the bunch was adopted as the basic variable and the others were considered the explanatory variables. The study of direct and indirect effects showed that the character output is much influenced by the environment in the first cycle, and the following production cycle is much influenced by vegetative traits, especially number of leaves at harvest. Index terms: Musa spp., breeding, path-analysis.

${ }^{1}$ (Trabalho 080-12). Recebido em: 31-01-2012. Aceito para publicação em: 18-10-2012.

2Projeto financiado pelo CNPq; (2) Embrapa Acre, BR 364, km 14, Zona Rural, s/n, Caixa postal 321, CEP 69.908-970, Rio Branco-Acre. E-mails: lauro.lessa@embrapa.br, tadario.oliveira@embrapa.br, giselle.assis@embrapa.br;

${ }^{3}$ Embrapa Mandioca e Fruticultura Tropical, R. da Embrapa, s/n, CEP 44380-000, Cruz das Almas - BA. E-mails: edson.amorim@ embrapa.br, sebastião.silva@colaborador.embrapa.br 


\section{INTRODUÇÃO}

A cultura da banana assume importância social e econômica em mais de 80 países (SILVA et al., 2002). No Brasil, quarto maior produtor mundial, a cultura é explorada de norte a sul, assumindo papel importante, principalmente nas pequenas propriedades rurais. No Acre, a bananicultura movimenta a economia do Estado e gera empregos diretos e indiretos, além de representar importante fonte de renda aos agricultores menos capitalizados.

As cultivares tipo Prata (Pacovan, Prata e Prata-Anã) representam mais de $60 \%$ da área cultivada com banana no Brasil. Apesar dessa expressividade, essas cultivares são sucetíveis às principais pragas da cultura (SILVA et al., 2006), o que pode ocasionar perdas de produção de até $100 \%$.

Para solucionar este problema, o programa de melhoramento de bananeira, coordenado pela Embrapa Mandioca e Fruticultura, vem selecionando novos genótipos que são resistentes às principais pragas da cultura, além de mais produtivos (SILVA et al., 1998; 2000; OLIVEIRA et al., 2008).

A produtividade em bananeira é um caráter complexo que resulta da associação de diferentes fatores, influenciados pelo ambiente. Assim, para que a seleção seja realizada de maneira eficiente, faz-se necessário o conhecimento das associações entre caracteres de grande importância para a cultura (AMORIM et al., 2008), principalmente se a seleção em um deles apresenta dificuldades, em razão da baixa herdabilidade e/ou tenha problemas de medição e identificação.

Porém, o simples estudo das associações entre caracteres não permite conhecer as relações de causa e efeito envolvendo um complexo de variáveis. A complexidade desses fatores e a necessidade de maior eficiência no processo de seleção requerem o desdobramento das estimativas de correlação. Tal desdobramento pode ser realizado pela análise de trilha, desenvolvida por Wrigth $(1921,1923)$ e detalhada por Li (1975).

A análise de trilha compreende o estudo de causas envolvidas nas associações entre caracteres e decompõe a correlação existente em efeitos diretos e indiretos, por meio de uma variável principal (KUREK et al., 2001). Estudos envolvendo respostas a efeitos diretos e indiretos foram realizados em diversas culturas, tais como: pimentão (TAVARES et al., 1999), feijão (KUREC et al., 2001; FURTADO et al., 2002), batata (CAVALCANTE et al., 2006), trigo (VIEIRA et al., 2007), mandioca (GOMES et al., 2007), maracujá (NEGREIROS et al., 2007) e girassol (AMORIM et al., 2008).
Em bananeira,são poucos os relatos do uso da análise de trilha visando a estimar efeitos diretos e indiretos sobre variáveis de produção. Assim, estudos desta natureza podem auxiliar ao melhorista na tomada de decisões, indicando modificações de um caráter ocasionado pela seleção de outro, envolvendo um conjunto de variáveis que apresentam relações entre si. Este trabalho tem por objetivo estudar os efeitos diretos e indiretos de características vegetativas sobre o caráter produção em bananeira, em três ciclos.

\section{MATERIAL E MÉTODOS}

O trabalho foi conduzido na Embrapa Acre, em Rio Branco, Acre. O município está situado a $10^{\circ} 01^{\prime}$ de latitude sul e $67^{\circ} 42^{\prime}$ de longitude oeste, a uma altitude de $160 \mathrm{~m}$. O clima é do tipo AWI (quente e úmido), conforme a classificação de Köppen, com temperatura máxima de $31,60^{\circ} \mathrm{C}$, temperatura mínima de $21,40^{\circ} \mathrm{C}$, precipitação anual de $1.544,30$ $\mathrm{mm}$ e umidade relativa de $83 \%$. O experimento foi implantado em um Argissolo Vermelho-Amarelo distrófico, de textura média e bem drenado.

Os genótipos avaliados foram Preciosa, Japira, Pacovan-Ken, Pacovan, BRS Platina, PrataAnã, ST12-31, Nanicão, Grande Naine, Calipso, Ambrosia, Bucaneiro e FHIA-02, selecionados em conjunto com a Embrapa Mandioca e Fruticultura (Tabela 1). O material vegetal usado no plantio consistiu em mudas micropropagadas. O plantio foi conduzido sem irrigação, com os tratos culturais recomendados para a cultura da bananeira citadas por Silva et al. (2011), e as adubações foram feitas com base na análise de solo.

As características avaliadas foram altura de plantas (ALT - m), diâmetro do pseudocaule (DPC $\mathrm{cm}$ ), número de folhas na floração (NFF), número de folhas na colheita (NFC), peso do cacho (PCH - $\mathrm{kg}$ ) e número de pencas no cacho (NPE).

$\mathrm{O}$ experimento foi implantando em blocos ao acaso, com cinco repetições e 13 tratamentos. A parcela foi constituída de 20 plantas, das quais, seis eram úteis, no espaçamento $3,0 \mathrm{~m} \times 2,0 \mathrm{~m}$. Como bordadura, foi utilizada a cultivar Grande Naine. Realizou-se análise de variância para cada ciclo de colheita e estimaram-se os coeficientes de correlação fenotípica, utilizando-se do programa SAS. Os coeficientes de trilha foram estimados para cada ciclo, utilizando-se das matrizes de correlação fenotípica, por meio do programa computacional GENES.

Adotou-se o diagrama causal, utilizandose como variável básica do peso do cacho (PCH), 
e como variáveis explicativas da altura de plantas (ALT), do diâmetro do pseudocaule (DPC), do número de folhas na floração (NFF) e na colheita (NFC) e do número de pencas (NPE), conforme ilustra a Figura 1. Antes de efetuar a análise de trilha, foi realizado um diagnóstico de multicolinearidade no conjunto de dados em estudo, utilizando a Tabela de Classificação de Montgomery \& Peck, em que: $\mathrm{NC}<100$ - colinearidade fraca; $100<\mathrm{NC}<1.000$ - colinearidade de forte a moderada; $\mathrm{NC}>1.000$ colinearidade severa.

\section{RESULTADOS E DISCUSSÃO}

O diagnóstico de multicolinearidade, realizado pelo programa computacional GENES (CRUZ, 2006), evidenciou número de condição (NC) menor que 100 para todos os ciclos estudados ( $1^{\circ}$ Ciclo 32,47; $2^{\circ}$ Ciclo 56,74; $3^{\circ}$ Ciclo 71,13), conforme Tabela de Classificação de Montgomery \& Peck, indicando colinearidade fraca e que há pouca dependência linear entre as variáveis independentes (COIMBRA et al., 2005).

Pela análise de variância, observa-se variabilidade entre os genótipos e os ciclos em todas as variáveis estudadas (Tabela 2). As correlações fenotípicas, em sua maioria, foram significativas (Tabela 3). A altura de plantas, que é um descritor importante por influenciar diretamente na densidade de plantio e manejo da cultura, com consequências na produção (ARANTES et al., 2010), apresentou, nos três ciclos estudados, maior correlação com o diâmetro do pseudocaule do que com o número de folhas na floração. Resultados semelhantes foram observados por Lima Neto et al. (2003), estudando correlações em genótipos de bananeira.

O número de pencas por cacho apresentou associações significativas e negativas com a altura de plantas (Tabela 3). O mesmo foi observado por Donato et al. (2006), estudando correlações em 13 genótipos de bananeira em Guanambi, Estado da Bahia.

O peso do cacho apresentou estimativas positivas de magnitude mediana com o número de folhas na colheita (Tabela 3). Segundo Lessa et al. (2010), plantas que retêm maior número de folhas na colheita, tendem a apresentar cachos mais pesados. Resultados semelhantes foram obtidos por Donato et al. (2006) e Lima Neto et al. (2003).

Analisando as correlações fenotípicas, observa-se que as relações entre altura de plantas (ALT) e peso do cacho (PCH) foram de baixas magnitudes e não significativas (Tabela 3 ). Porém, ao desdobrar as correlações em efeitos diretos e indiretos, nota-se que, no primeiro e terceiro ciclos de avaliação da produção, a ALT apresentou alta correlação com a variável básica PCH (efeito direto), indicando que a produção é influenciada pela altura de plantas (Tabela 4). No segundo ciclo, o efeito indireto de NFC, via ALT, apresentou estimativa de maior magnitude.

Verifica-se, ainda, que os efeitos indiretos de ALT em PCH via DPC (terceiro ciclo), NFF (segundo ciclo) e NPE (primeiro, segundo e terceiro ciclos) interferiram, em sentido desfavorável, na estimativa total das correlações (Tabela 4). Correlações de alta magnitude entre peso do cacho e altura de plantas foram observados por Lima Neto et al. (2003). Já Donato et al. (2006), observaram estimativas de correlação de baixas magnitudes. Isso evidencia que este comportamento pode ter sido induzido por condições ambientais, durante os ciclos de produção.

No primeiro ciclo, o efeito indireto de DPC em PCH via ALT, NFC e NPE apresentou efeitos superiores ao observado no efeito direto sobre a variável básica. Já no segundo ciclo, observa-se uma tendência de aumento na estimativa de efeito direto de DPC em PCH, porém o efeito indireto de DPC em PCH via NFF e NFC apresentou estimativas de maior valor. No terceiro ciclo, observa-se um efeito direto alto de DPC sobre a variável básica, porém de forma negativa. Este resultado permite inferir que plantas de maior diâmetro de pseudocaule (DPC) tendem a apresentar cachos menos pesados (SIRISENA;SENANAYAKE, 2000). As correlações totais entre DPC e PCH apresentaram valores de baixa magnitude nos três ciclos estudados (Tabela 4).

Na variável NFF, nota-se que, nos três ciclos, os efeitos indiretos de NFF via ALT e NFC foram os principais determinantes das alterações em PCH. Já em NFC, observa-se que os efeitos diretos em PCH são de elevada magnitude nos três ciclos de produção (Tabela 4). Diante disso, pode-se inferir que plantas com o maior número de folhas na colheita tendem a apresentar cachos mais pesados e que é possível a seleção indireta para peso do cacho $(\mathrm{PCH})$, por meio do número de folhas na colheita (NFC), tendo em vista, ainda, que a hipótese de verdadeira associação entre esses caracteres aponta também para a necessidade da aplicação de um esquema seletivo e restrito de seleção, a fim de eliminar os efeitos indiretos indesejáveis.

$\mathrm{O}$ número de pencas na colheita (NPE) apresentou, no primeiro e terceiro ciclos, efeitos diretos medianos em PCH, porém os efeitos indiretos via ALT contribuíram desfavoravelmente na estimativa total. Já no segundo ciclo, nota-se que o efeito direto de NPE foi o principal determinante 
em PCH (Tabela 4).

No primeiro ciclo, o coeficiente de determinação da análise de trilha apresentou magnitude de 0,50 , indicando que a maior parte da variação na variável básica $(\mathrm{PCH})$ não foi totalmente explicada pelas variáveis independentes e, devido ao alto efeito residual, infere-se que o ambiente foi o principal responsável pela variação exposta. Já no segundo e terceiro ciclos, observam-se coeficientes de determinação superiores ao encontrado no primeiro ciclo, evidenciando que as variáveis explicativas foram as principais responsáveis pela variação na variável principal - PCH (Tabela 4).

TABELA 1- Características dos genótipos de bananeira avaliados em Rio Branco-Acre.

\begin{tabular}{lccc}
\hline Genótipos $^{(1)}$ & Grupo genômico & Tipo & Genealogia e características \\
\hline Preciosa & AAAB & Prata & PV42-85, híbrido (Pacovan x diploide M53). \\
Japira & AAAB & - & PV42-142, híbrido (Pacovan x diploide M53). \\
Pacovan-Ken & AAAB & - & PV42-68, híbrido (Pacovan x diploide M53). \\
Pacovan & AAB & - & Cultivar mutante da Prata comum, de porte alto. \\
BRS Platina & AAAB & - & Híbrido (Prata Anã x diploide M53). \\
Prata-Anã & AAB & - & Cultivar mutante de Branca, com frutos tipo Prata, \\
ST12-31 & AAAB & - & Hébrido (Prata São Tomé x Lidi), porte alto. \\
FHIA-02 & - & Gros Michel Tetraploide de genealogia desconhecida. \\
Nanicão & AAA & Cavendish & Mutante da Nanica, de porte médio. \\
Grande Naine & AAA & - & Mutante da Nanica, de porte médio a baixo. \\
Calipso & AAAA & Gros Michel Híbrido tipo Gros Michel, de porte médio a alto. \\
Ambrosia & AAAA & - & Híbrido tipo Gros Michel, de porte médio a alto. \\
Bucaneiro & AAAA & - & Híbrido tipo Gros Michel, de porte médio a alto. \\
\hline
\end{tabular}

${ }^{(2)}$ Híbrido selecionado pela Fundacion Hondureña de Investigacion Agrícola.

TABELA 2- Características agronômicas avaliadas em 13 genótipos de bananeira durante três ciclos de produção em Rio Branco-Acre.

\begin{tabular}{cccccc}
\hline Variáveis & Ciclos & Mínimo & Máximo & Média & Desvio-padrão \\
\hline \multirow{4}{*}{ Altura de plantas $(\mathrm{m})$} & 1 Ciclo & 1,61 & 3,45 & 2,50 & $\pm 1,10$ \\
& 2 Ciclo & 1,70 & 3,78 & 2,90 & $\pm 1,20$ \\
& 3 Ciclo & 1,84 & 4,44 & 3,13 & $\pm 1,55$ \\
\hline \multirow{2}{*}{ Diâmetro do pseudo-caule } & 1 Ciclo & 14,07 & 23,38 & 17,82 & $\pm 3,57$ \\
(cm) & 2 Ciclo & 12,39 & 26,84 & 22,14 & $\pm 3,70$ \\
& 3 Ciclo & 16,98 & 28,38 & 23,23 & $\pm 5,06$ \\
\hline \multirow{2}{*}{ Número de folhas na } & 1 Ciclo & 3,33 & 14,16 & 9,15 & $\pm 5,40$ \\
floração & 2 Ciclo & 6,66 & 11,16 & 8,53 & $\pm 1,84$ \\
& 3 Ciclo & 5,75 & 13,16 & 9,00 & $\pm 3,75$ \\
\hline \multirow{2}{*}{ Número de folhas } & 1 Ciclo & 0,00 & 4,83 & 0,93 & $\pm 2,85$ \\
na colheita & 2 Ciclo & 0,00 & 6,66 & 1,76 & $\pm 3,53$ \\
\hline & 3 Ciclo & 0,00 & 6,83 & 1,42 & $\pm 3,76$ \\
\hline \multirow{2}{*}{ Número de pencas } & 1 Ciclo & 4,75 & 8,75 & 6,19 & $\pm 1,70$ \\
& 2 Ciclo & 4,66 & 9,20 & 6,55 & $\pm 2,10$ \\
& 3 Ciclo & 0,58 & 9,17 & 6,83 & $\pm 2,08$ \\
\hline \multirow{2}{*}{ Peso do cacho (kg) } & 1 Ciclo & 3,48 & 13,38 & 7,84 & $\pm 4,31$ \\
& 2 Ciclo & 2,25 & 15,00 & 7,78 & $\pm 5,21$ \\
& 3 Ciclo & 5,25 & 21,58 & 10,71 & $\pm 6,53$ \\
\hline
\end{tabular}


TABELA 3 - Correlações fenotípicas entre os caracteres altura de plantas (ALT), diâmetro do pseudocaule (DPC), número de folhas na floração (NFF) e na colheita (NFC), número de pencas (NPE) e peso de cacho $(\mathrm{PCH})$, em 13 genótipos de bananeira, em três ciclos de produção, em Rio Branco-Acre.

\begin{tabular}{cllcccc}
\hline Caracteres & Ciclos & DPC & NFF & NFC & PCH & NPE \\
\hline \multirow{2}{*}{ Altura de plantas } & $1^{\circ}$ Ciclo & $0,69^{* *}$ & $0,48^{*}$ & $-0,07^{\text {ns }}$ & $0,17^{\text {ns }}$ & $-0,81^{* *}$ \\
& $2^{\circ}$ Ciclo & $0,66^{* *}$ & $0,68^{* *}$ & $0,50^{*}$ & $0,15^{\text {ns }}$ & $-0,66^{* *}$ \\
& $3^{\circ}$ Ciclo & $0,83^{* *}$ & $0,35^{*}$ & $0,15^{\text {ns }}$ & $0,27^{\text {ns }}$ & $-0,58^{* *}$ \\
\hline Diâmetro & $1^{\circ}$ Ciclo & & $0,72^{* *}$ & $-0,21^{\text {ns }}$ & $0,05^{\text {ns }}$ & $-0,50^{* *}$ \\
do pseudocaule & $2^{\circ}$ Ciclo & & $0,64^{* *}$ & $0,46^{*}$ & $0,53^{* *}$ & $-0,41^{* *}$ \\
& $3^{\circ}$ Ciclo & & $0,31^{*}$ & $0,08^{\text {ns }}$ & $0,04^{\text {ns }}$ & $-0,37^{*}$ \\
\hline Número de folhas & $1^{\circ}$ Ciclo & & & $0,55^{* *}$ & $0,49^{*}$ & $-0,25^{*}$ \\
na floração & $2^{\circ}$ Ciclo & & & $0,84^{* *}$ & $0,38^{*}$ & $-0,47^{* *}$ \\
& $3^{\circ}$ Ciclo & & $0,90^{* *}$ & $0,63^{* *}$ & $-0,07^{\text {ns }}$ \\
\hline Número de folhas & $1^{\circ}$ Ciclo & & & $0,61^{* *}$ & $0,19^{\mathrm{ns}}$ \\
na colheita & $2^{\circ}$ Ciclo & & & $0,71^{* *}$ & $-0,13^{\text {ns }}$ \\
& $3^{\circ}$ Ciclo & & & & $0,74^{* *}$ & $0,02^{\text {ns }}$ \\
\hline Peso do & $1^{\circ}$ Ciclo & & & & $0,11^{\text {ns }}$ \\
cacho & $2^{\circ}$ Ciclo & & & & & $0,31^{*}$ \\
& $3^{\circ}$ Ciclo & & & & & \\
\hline
\end{tabular}

${ }^{* *} \mathrm{e}^{*}$ Significativos a $1 \%$ e $5 \%$, respectivamente ${ }^{\text {ns }}$ não significativo.

TABELA 4- Efeitos diretos e indiretos dos caracteres altura de plantas (ALT), diâmetro do pseudocaule (DPC), número de folhas na floração (NFF) e na colheita (NFC) e número de pencas no cacho (NPE), sobre a variável básica peso do cacho $(\mathrm{PCH})$, de 13 genótipos de bananeira.

\begin{tabular}{|c|c|c|c|c|}
\hline \multirow{8}{*}{$\begin{array}{c}\text { Caráter } \\
\text { ALT }\end{array}$} & \multirow{2}{*}{ Efeito } & \multicolumn{3}{|c|}{ Estimativa } \\
\hline & & $1^{\circ}$ Ciclo & $2^{\circ}$ Ciclo & $3^{\circ} \mathrm{Ciclo}$ \\
\hline & Efeito direto sobre $\mathrm{PCH}$ & 0,6008 & 0,2557 & 1,0106 \\
\hline & Efeito indireto via DPC & $-0,0030$ & $-0,1428$ & $-0,4968$ \\
\hline & Efeito indireto via NFF & 0,0141 & $-0,2312$ & $-0,1329$ \\
\hline & Efeito indireto via NFC & $-0,0393$ & 0,5099 & 0,1468 \\
\hline & Efeito indireto via NPE & $-0,4036$ & $-0,2437$ & $-0,2611$ \\
\hline & $r_{f}$ & 0,1691 & 0,1479 & 0,2665 \\
\hline \multirow[t]{6}{*}{ DPC } & Efeito direto sobre $\mathrm{PCH}$ & $-0,0043$ & $-0,2180$ & $-0,5964$ \\
\hline & Efeito indireto via ALT & 0,4123 & 0,1675 & 0,8417 \\
\hline & Efeito indireto via NFF & 0,0021 & $-0,2181$ & $-0,1174$ \\
\hline & Efeito indireto via NFC & $-0,1149$ & 0,4713 & 0,0802 \\
\hline & Efeito indireto via NPE & $-0,2492$ & $-0,1500$ & $-0,1674$ \\
\hline & $\mathrm{r}_{f}$ & 0,046 & 0,0527 & 0,0406 \\
\hline \multirow[t]{6}{*}{ NFF } & Efeito direto sobre $\mathrm{PCH}$ & 0,02959 & $-0,3403$ & $-0,3806$ \\
\hline & Efeito indireto via ALT & 0,2863 & 0,1737 & 0,3530 \\
\hline & Efeito indireto via DPC & $-0,0003$ & $-0,1397$ & $-0,1840$ \\
\hline & Efeito indireto via NFC & 0,3000 & 0,8623 & 0,8770 \\
\hline & Efeito indireto via NPE & $-0,1234$ & $-0,1750$ & $-0,0302$ \\
\hline & $\mathrm{r}_{f}$ & 0,4924 & 0,381 & 0,6351 \\
\hline \multirow[t]{6}{*}{ NFC } & Efeito direto sobre $\mathrm{PCH}$ & 0,5422 & 1,0223 & 0,9739 \\
\hline & Efeito indireto via ALT & $-0,0435$ & 0,1275 & 0,1523 \\
\hline & Efeito indireto via DPC & 0,0009 & $-0,1005$ & $-0,0491$ \\
\hline & Efeito indireto via NFF & 0,0163 & $-0,2871$ & $-0,3427$ \\
\hline & Efeito indireto via NPE & 0,0961 & $-0,0484$ & 0,0072 \\
\hline & $\mathrm{r}_{\mathrm{f}}$ & 0,6121 & 0,7139 & 0,7415 \\
\hline \multirow[t]{8}{*}{ NPE } & Efeito direto sobre $\mathrm{PCH}$ & 0,4986 & 0,3683 & 0,4521 \\
\hline & Efeito indireto via ALT & $-0,4863$ & $-0,1692$ & $-0,5837$ \\
\hline & Efeito indireto via DPC & 0,0022 & 0,0888 & 0,2209 \\
\hline & Efeito indireto via NFF & $-0,0073$ & 0,1617 & 0,0255 \\
\hline & Efeito indireto via NFC & 0,1045 & $-0,1343$ & 0,0156 \\
\hline & $r_{f}$ & 0,1117 & 0,3153 & 0,1303 \\
\hline & $\mathrm{R}^{2}$ & 0,5035 & 0,7426 & 0,7844 \\
\hline & Efeito residual & 0,7046 & 0,5073 & 0,4643 \\
\hline
\end{tabular}

$\mathrm{r}_{\mathrm{f}}$ : correlação fenotípica. 


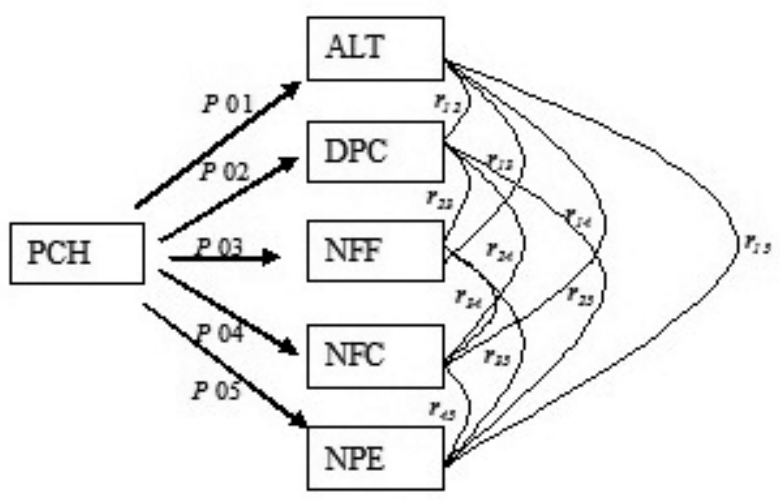

FIGURA 1- Diagrama causal em cadeia, mostrando o inter-relacionamento dos efeitos diretos e indiretos das variáveis explicativas (altura de plantas - ALT, diâmetro do pseudocaule - DPC, número de folhas na floração - NFF, número de folhas na colheita - NFC, e número de pencas no cacho - NPE), e a variável básica, peso do cacho (PCH).

\section{CONCLUSÕES} estudados.

1-Existe variabilidade entre os genótipos

2-O estudo dos efeitos diretos e indiretos evidencia que o caráter produção é bastante influenciado pelo ambiente no primeiro ciclo e, nos ciclos seguintes, a produção é muito influenciada pelas características vegetativas, como altura de plantas e principalmente número de folhas na colheita.

\section{AGRADECIMENTOS}

Ao CNPq, pelo apoio financeiro. À Embrapa Mandioca e Fruticultura, pela concessão dos materiais estudados, e à Embrapa Acre, pela área e o apoio de campo.

\section{REFERÊNCIAS}

AMORIM, E.P.; RAMOS, N.P.; UNGARO, M.R.G.; KIIHL, T.A.M. Correlações e análise de trilha em girassol. Bragantia, Campinas, v.67, n.2, p.307316, 2008.

ARANTES, A.M.; DONATO, S.R.L.; SILVA, S de O. e. Relação entre características morfológicas e componentes de produção em plátanos. Pesquisa Agropecuária Brasileira, Brasília, v.45, p.224227, 2010.
CAVALCANTE, J.T.; FERREIRA, P.V.; SOARES, L.; BORGES, V.; SILVA, P.P. da; SILVA, J.W. da. Análise de trilha em caracteres de rendimento de clones de batata-doce (Ipomoea batatas (L.) Lam). Acta Scientiarum Agronomy, Maringá, v. 28, n. 2, p. 261-266, 2006.

COIMBRA, J.L.M.; BENIN, G.; VIEIRA, E.A.; OLIVEIRA, A.C.; CARVALHO, F.I.F.; GUIDOLIN, A.F.; SOARES, A.P. Conseqüências da multicolinearidade sobre a análise de trilha em canola. Ciência Rural, Santa Maria, v.35, n.2, p.347-352, 2005.

CRUZ, C.D. Programa genes - Biometria. Viçosa: Editora UFV, 1. ed. 2006,382p.

DONATO, S.L.R.; SILVA, S. de O. e; LUCCA FILHO, O.A.; LIMA, M.B.; DOMINGUES, H.; ALVES, J.S. Correlação entre caracteres da planta e do cacho em bananeira (Musa spp.). Ciência e Agrotecnologia, Lavras, v.30, p.21-30, 2006.

FURTADO, M.R.; CRUZ, C.D.; CARDOSO, A.A.; COELHO, A.D.F.; PETERNELLI, L.A. Análise de trilha do rendimento do feijoeiro e seus componentes primários em monocultivo e em consórcio com a cultura do milho. Ciência Rural, Santa Maria, v. 32, n. 2, p. 217-220, 2002.

GOMES, C.N.; CARVALHO, S.P.; JESUS, A.M.S.; CUSTÓDIO, T.N. Caracterização morfoagronômica e coeficientes de trilha de caracteres componentes da produção em mandioca. Pesquisa Agropecuária Brasileira, Brasília, v.42, n.8, p.1121-1130, 2007. 
KUREC, A.J.; CARVALHO, FIF de; ASSMAN, I.C.; MARCHIORO, V.S.; CRUZ, P.J. Análise de trilha como critério de seleção indireta para rendimento de grãos em feijão. Revista Brasileira de Agrociência, Pelotas, v. 7 n. 1, p. 29-32, 2001.

LESSA, L.S.; LEDO, C.A.S.; SILVA, S.O.; AMORIM, E.P.; OLIVEIRA, T.K. Características agronômica de híbridos diploides de bananeira em três ciclos de produção em Cruz das Almas, Bahia. Revista Brasileira de Fruticultura, Jaboticabal, v. 32, n. 1, p. 213-221, 2010.

LIMA NETO, F.P.; SILVA, S.O.; FLORES, J.C.O.; JESUS, O.N.; PAIVA, L.E. Relação entre caracteres de rendimento e desenvolvimento em genótipo de bananeira. Magistra, Cruz das Almas, v. 15, n. 2, p. 275-281, 2003.

NEGREIROS, J.R.S.; ÁLVARES, V.S.; BRUCKNER, C.H.; MORGADO, M.A.D.; CRUZ, C.D. Relação entre características físicas e o rendimento de polpa de maracujá-amarelo. Revista Brasileira de Fruticultura, Jaboticabal, v. 29, n. 3, p. 546-549, 2007.

OLIVEIRA, T.K. de; LESSA, L.S.; SILVA, S. de O. e; OLIVEIRA, J.P. Características agronômicas de genótipos de bananeira em três ciclos de produção em Rio Branco, Acre. Pesquisa Agropecuária Brasileira, Brasília, v. 43, n. 8, p. 1003-1010, 2008.

SILVA, S.O.; MATOS A.P.; CORDEIRO, Z.J.M.; LIMA, M.J.C.; AMORIM, E.P. Avaliação de genótipos tetraploides de bananeira cultivados em área infestada pelo agente causal do mal-do-Panamá. Revista Brasileira de Fruticultura, Jaboticabal, v. 33, p. 125-132, 2011.

SILVA, S. de O. e; FLORES, J.C.O.; LIMA NETO, F.P. Avaliação de cultivares e híbridos de bananeira em quatro ciclos de produção. Pesquisa Agropecuária Brasileira, Brasília, v.37, p.15671574, 2002.
SILVA, S. de O. e; MATOS, A.P.; ALVES, E.J. Melhoramento genético da bananeira. Pesquisa Agropecuária Brasileira, Brasília,v.33, p.693-703, 1998.

SILVA, S. de O. e; PIRES, E.T.; PESTANA, R.K.N.; ALVES, J.S.; SILVEIRA, D.C. Avaliação de clones de banana Cavendish. Ciência e Agrotecnologia, Lavras, v.30, p.832-837, 2006.

SILVA, S. de O. e; ROCHA, S.A.; ALVES, E.J.; CREDICO, M.; PASSOS, A.R. Caracterização morfológica e avaliação de cultivares e híbridos de bananeira. Revista Brasileira de Fruticultura, Jaboticabal, v.22, p.161-169, 2000.

SIRISENA, J.A.; SENANAYAKE, S.G.J.N Estimation of variability parameters within 'Mysore' banana clones and their implication for crop improvement. Scientia Horticulturae, Amsterdam, v.84, n. 1-2, p. 49-66, 2000.

TAVARES, M.; MELO, A.M.T. de; SCIVITTARO, W.B. Efeitos diretos e indiretos e correlações canônicas para caracteres relacionados com a produção de pimentão. Bragantia, Campinas, v. 58, n. 1, p. $41-47,1999$.

VIEIRA, E.A.; CARVALHO, F.I.F.; OLIVEIRA, A.C. de; MARTINS, L.F.; BENIN, G.; SILVA, J.A.G.; COIMBRA, J.; MARTINS, A.F.; CARVALHO, M.F.; RIBEIRO, G. Análise de trilha entre os componentes primários e secundários do rendimento de grãos em trigo. Revista Brasileira de Agrociência, Pelotas, v. 13, n.2, p. 169-174, 2007.

WRIGHT, S. Correlation and causation. Journal of Agricultural Research, Washington, v.20, n.3, p.557-585, 1921.

WRIGHT, S. The theory of path coefficients - a replay to Nile's criticism. Genetics, Austin, v. 8, p. 239-255, 1923. 